\title{
Review on the Study of Dielectric Properties of Food Materials
}

\author{
Wondemu Bogale Teseme ${ }^{1,}$, , Helen Weldemichael Weldeselassie ${ }^{2}$ \\ ${ }^{1}$ Department of Food Technology and Process Engineering, Institute of Technology, Haramaya University, Dire Dawa, Ethiopia \\ ${ }^{2}$ Department of Food Process Engineering, Wolkite University, Wolkite, Ethiopia
}

Email address:

Wondimubogale080@gmail.com (W. B. Teseme), nelehwm@gmail.com (H. W. Weldeselassie)

${ }^{*}$ Corresponding author

To cite this article:

Wondemu Bogale Teseme, Helen Weldemichael Weldeselassie. Review on the Study of Dielectric Properties of Food Materials. American Journal of Engineering and Technology Management. Vol. 5, No. 5, 2020, pp. 76-83. doi: 10.11648/j.ajetm.20200505.11

Received: October 19, 2020; Accepted: November 5, 2020; Published: November 23, 2020

\begin{abstract}
Dielectric properties of foods are used to explain interactions of foods with electric fields. It determines the interaction of electromagnetic waves with matter and defines the charge density under an electric field. For engineering point of view, dielectric properties are the foremost important physical properties related to radio frequency and microwave heating, it is critical to possess knowledge of the dielectric properties of materials in products and process development and, within the modern design of dielectric heating system for the need of desired process. Dielectric properties are often categorized into two: dielectric constant and dielectric loss factor. Dielectric constant is the ability of a material to store microwave energy and dielectric loss factor is the ability of a material to dissipate microwave energy into heat. Dielectric properties of food materials are required for various applications in food industry like microwave (at 915 or $2450 \mathrm{MHz}$ ), radio wave (at 13.56, 27.12 or $40.68 \mathrm{MHz}$ ) and magnetic field processing. In this review, the dielectric properties of various food groups were listed such as; Cereal grains and oilseeds, Bakery product, Dairy products, Poultry products, Fruits and vegetables. Dielectric properties are utilized in fruit drying processes, protect food materials from insects that already present in dried fruits, pasteurization, sterilization, tempering of concentration of liquid foods such as fruit juices, identification, processing, quality monitoring of fats and oils and improvement during oil processing and storage. The dielectric studies of food materials are an important tool to identify the quality of food materials and to improve dielectric heating uniformity. Frequency, moisture content, phase change, storage time and temperature are main factors that influence the dielectric properties of food material.
\end{abstract}

Keywords: Dielectric Properties, Microwave, Radio Frequency, Food Material

\section{Introduction}

Dielectric properties of foods are important because they show microwave or radio frequency heating ability of food products. Dielectric properties also can be utilized in assessment of food quality. For engineering point of view, dielectric properties are the foremost important physical properties related with radio frequency and microwave heating, it is critical to possess knowledge of the dielectric properties of materials in products and process development and, within in the modern design of dielectric heating system for the need of desired process [1].

Dielectric properties are often categorized into two: dielectric constant and dielectric loss factor. Dielectric constant $\left(\varepsilon^{\prime}\right)$ is that the ability of a material to store microwave energy and dielectric is loss factor ( $\varepsilon ")$ is the ability of a material to dissipate microwave energy into heat. The parameter that measures microwave absorptivity is the loss factor. The values of dielectric constant and loss factor were play important roles in determining the interaction of microwaves with food [2].

Dielectrics are a category of materials that are poor conductors of electricity, in contrast to materials like metals that are generally good electrical conductors. Many materials, including living organisms and most agricultural products, conduct electric currents to some degree, but are still classified as dielectrics [3]. The electrical nature of these materials can be described by their dielectric properties, which influence the distribution of electromagnetic fields and 
currents within the region occupied by the materials, and which determine the behavior of the materials in electric fields. Thus, the dielectric properties determine how rapidly a material will warm up in radio frequency or microwave dielectric heating applications [4].

Dielectric properties are important characteristics determining interactions of materials with electromagnetic energy. When materials are exposed to the intense radio frequency (at 13.56, 27.12 and $40.68 \mathrm{MHz}$ ) or microwave electric fields (at 915 or $2450 \mathrm{MHz}$ for industrial heating applications and $2450 \mathrm{MHz}$ for domestic ovens; 5800 or $24225 \mathrm{MHz}$ for laboratory and research projects), the dielectric properties indicate the rate of dielectric heating (DH) [5]. The interactions between dielectric energy and food products at any given frequency range gives useful information related with the microwave or radio frequency processing $[6,7]$. Furthermore, the knowledge about dielectric properties is vital for developing successful and uniform pasteurization treatments to select the optimal frequency ranges by radio frequency (RF) and microwave heating energy [8].

Dielectric properties of materials are used for evaluating their interactions with electromagnetic energy. Dielectric properties of food materials are required for various applications in food industry like microwave (at 915 or 2450 $\mathrm{MHz}$ ), radio wave (at $13.56,27.12$ or $40.68 \mathrm{MHz}$ ) and magnetic field processing. So as to know the response of food materials to electromagnetic energy, dielectric parameters must be determined as a function of frequency, temperature, composition and moisture content [9].

Knowledge of the connection between frequency and dielectric properties is useful in determining the optimum frequency range in which the material has the desired dielectric characteristics for intended applications and useful in studying and developing heating processes or grading techniques based on electromagnetic energy [10], and also uses in the selection of proper packaging materials and cooking utensils and in the design of microwave and radio frequency heating equipment [11]. The moisture dependent dielectric properties in specific frequency ranges are often want to develop online moisture meters [12]. The possible selective dielectric heating for control of insects that infest stored grain [13]. The dielectric properties data also are important within the investigation of seed treatment to enhance germination reported that dielectric measurements also can be want to measure density and water activity [14].

\section{Dielectric Properties}

Dielectric properties have big importance and applications for foods, which are associated with novel microwave or radio frequency heating treatments. These are the most parameters that provide information and during heating by microwaves or high frequency electromagnetic radiations, the heating performance of foods is suffering from many variables [15]. In order to determine the absorption of microwave energy, heating attitude of foods during microwave heating, and analyses the result, the dielectric properties are used to associate with electromagnetic fields
[16].

The dielectric properties describe how materials interact with electromagnetic radiation. Natural biological materials absorb only the electric part of the electromagnetic field. Agricultural materials are practically non-magnetic, as they contain only trace amounts of magnetic material, such as iron and cobalt [17]. Dielectric properties of a material are described by the relative complex permittivity ( $\varepsilon^{*}$, relative to that of free space). Permittivity indicates the dielectric properties that lead immersion and emission of the electromagnetic currents at phases including the attenuation of waves within the materials. The absolute permittivity of a vacuum, $\varepsilon_{0}$, the speed of light $\left(\mathrm{c}^{2}\right)$ and therefore the magnetic constant $(\mu \mathrm{o})$ are often combined by the Equation [18].

$$
C^{2} \mu_{0} \varepsilon_{0}=1
$$

The value of $\varepsilon_{0}$ is $8.854 \times 10-12 \mathrm{~F} / \mathrm{m}$.

\subsection{Dielectric Properties of Selected Food Materials}

\subsubsection{Cereal Grains and Oilseeds}

Grain moisture meters, which sense the moisture content through correlations between the R F dielectric properties of the grain, and its moisture content, are in common use for more than 50 years, recent advances are reported in use of higher frequencies within the microwave range for grain, and seed moisture sensing [19]. The dielectric properties of cereal grains and oilseeds are essential for understanding their electric behaviour, and the development of indirect nondestructive methods for determining their physical properties [20]. The dielectric properties of food grains are known to be dependent on moisture content, temperature, and frequency used. Dielectric spectroscopy measurements were carried out on ground hard red winter wheat at frequencies from 10 to $1,800 \mathrm{MHz}$ over the temperature range from 25 to $95^{\circ} \mathrm{C}$ [21]. In agriculture, the dielectric properties of grains have been widely used to determine the moisture content of grain, because of their usefulness for rapid moisture content sensing [22].

Dielectric properties of chickpea, green pea, lentil, and soybean flour samples at different frequencies $(10-1,800$ $\mathrm{MHz}$ ), temperatures $\left(20-90^{\circ} \mathrm{C}\right)$, and moisture contents (about 8-21 g/100 g)/water activities (0.3-0.9) were measured by an open-ended coaxial-line probe, and impedance analyze [23]. The dielectric properties of flax seed were measured within the ranges of $5.92 \%-22.18 \%$ on dry basis (d.b.) for moisture content, and $50 \mathrm{kHz}-10 \mathrm{MHz}$ for frequency of applied electric field employing a parallel-plate capacitor sample holder [24].

\subsubsection{Bakery Product}

Microwave and radio-frequency heating have also been used for baking processes. The dielectric properties for bread and flour are measured mostly at high frequencies. The dielectric constant and loss factor of baked dough at $27 \mathrm{MHz}$ was found to be significantly useful for the baking industry operating at both radio frequency and microwave spectrums 
[25]. The dielectric constants and loss factors of bakery products decreased as frequency increased [26]. While increasing moisture content leads to no change in loss factor in general except chesnut flour, dielectric constant values changes depending on the composition of products. The chemical compositions have direct effects on the dielectric properties of food materials. Even though the main effect belongs to the moisture content, the content of salt, and other minerals which are associated the dielectric properties [27].

\subsubsection{Dairy Products}

Dielectric properties of dairy products are relatively scarce. [28], studied the complex permittivity of milk at room temperature $\left(17-20^{\circ} \mathrm{C}\right)$ over the frequency range of $1-20$ $\mathrm{GHz}$, and suggested that they may be helpful to roughly determine the milk's content in terms of ionic compounds, fats, and carbohydrates and proteins. The dielectric properties of milk and its constituents at $2.45 \mathrm{GHz}$ were reported by [29]. The dielectric properties of a macaroni and cheese food stuff and found that dielectric constant decreased with increasing temperature and loss factor increased at higher temperatures at frequencies of $27,40,915$ and $1,800 \mathrm{MHz}$ [30]. The dielectric constant increased at 27 and $40 \mathrm{MHz}$ and decreased at 915 and $1,800 \mathrm{MHz}$ as the temperature increased from 20 to $121^{\circ} \mathrm{C}$ and loss factor increased sharply with this increase in temperature at 27 and $40 \mathrm{MHz}$, but increased mildly at 915 and $1,800 \mathrm{MHz}$, for macaroni and cheese [31]. Dielectric constant decreased gradually as frequency increased for cheeses over the frequency range $0.3-3 \mathrm{GHz}$ and loss factor generally increased with increasing temperature for high and medium moisture/fat ratio cheeses [32]. It's possible to add salt on butter to preserve from contamination. Dielectric properties of butter with and without salt over the Microwave frequency range covering 500-3,000 MHz were studied [33]. They found that dielectric spectra of unsalted butter differed significantly from the salted one as a function of temperature and moisture content. The consequences of dissolved salts on dielectric loss in milk were also investigated in chemical simulation studies, which showed that predictions of milk dielectric loss factor based on conductivities implied by ash contents needed to be corrected for binding and non-binding interactions of milk salts Solutions and suspensions [29].

\subsubsection{Poultry Products}

Some dielectric spectroscopy measurements are taken recently on poultry products in exploratory work on quality sensing [34]. Dielectric properties values for fresh chicken breast meat in the 10 to $1800-\mathrm{MHz}$ frequency range at temperatures from $5^{\circ} \mathrm{C}$ to $65^{\circ} \mathrm{C}$. Probable potential for using dielectric properties to assess meat quality characteristics was indicated. Dielectric spectroscopy measurements were also taken on the albumen and yolk of fresh chicken eggs at weekly intervals during 5 weeks of storage (Guo et al., 2007). Dielectric properties from $10-1800 \mathrm{MHz}$ for the fresh eggs. The albumen has higher values for both the dielectric constant and loss factor than the yolk at any given frequency. Dielectric properties changed during the storage period, but they didn't correlate well with traditional quality factors for the eggs [19].

The dielectric properties of egg whites depend upon protein contents whose denaturation temperatures change from 58 to $84^{\circ} \mathrm{C}$ [35]. The dielectric constants and loss factors of egg whites increased with increasing temperatures at $27 \mathrm{MHz}$ [36]. While the dielectric constants decreased with increasing temperatures at $915 \mathrm{MHz}$, loss factors increased which means egg whites are often cooked more quickly at $915 \mathrm{MHz}$ [35]. It is also indicated that, the dielectric behaviors of egg white, yolk, and albumen were revealed as almost like one another for higher frequencies and dielectric constants and loss factors of egg white, yolk, and albumen decreased with increasing temperature at 2450 $\mathrm{MHz}$ [37].

\subsubsection{Fruits and Vegetables}

Because of the necessity for rapid nondestructive quality measurements for fresh fruits and vegetables, the dielectric properties of a few products were measured at microwave frequencies [12]. Dielectric constant and loss factor of fruits and vegetables decrease with increasing frequency [9]. Moisture content is additionally critical for these food groups. General, dielectric constant increase with increasing moisture content while loss factor decrease for some fruits and vegetables, therefore the tendency varies with types of vegetables or fruits. Some fruits undergo change during the storage period. According to a study, the dielectric constant and loss factor remain mostly same throughout storage at refrigerator [38]. Similarly, dielectric constant values remain the same for potato starch, tapioca flour, broccoli powder, and onion powder with increasing frequency, while loss factors of them were decreasing with increasing frequency. Besides loss factor values were very low because of the very low water content of the samples [39]. For berry samples (blackberry, raspberry, and strawberry), the permittivity increased with increasing temperature and decreased with increasing frequency; the imaginary permittivity decreased with temperature and increased with frequency [40].

Dielectric properties of mangoes were measured using an open-ended coaxial-line probe with an impedance analyzer at frequency of $(1-1,800 \mathrm{MHz})$, temperature of $\left(20-60^{\circ} \mathrm{C}\right)$ and ripening at $21^{\circ} \mathrm{C}$ for 16 days storage [38]. Dielectric properties values decreased with increasing frequency, but this reduction was larger for the loss factor than that for the dielectric constant. Dielectric properties of a commercial apple juice product were also measured over the $200 \mathrm{MHz}$ to twentyGHz frequency range [41]. The temperature dependence of the dielectric properties of the apple juice at the higher frequencies is also very similar to that of pure liquid water, with the relaxation frequency for pure water shifting from below $20 \mathrm{GHz}$ to higher frequencies as temperature increases [42].

\subsection{Effects of Composition of Food Materials on Dielectric Properties}

The effect of starch, lipid, and protein on dielectric 
behavior is interested because it can explain the interaction between the food matrix and electromagnetic fields [43], which may be useful for formulating functional food. In present, the foremost popular method for measuring the dielectric properties of foods is open-ended coaxial probe [44], which is non-destructive method. It's easy to use by contact the probe with the material being tested. After that, the dielectric properties are calculated from the phase, and amplitude of the reflected signal [5]. Moreover, chemical composition affects the thermal properties of food such as thermal conductivity $(\mathrm{k})$ and specific heat capacity $(\mathrm{Cp})$. The dielectric and thermal properties can be used to predict heating rates, which can describe the behavior of food materials when subjected to the microwave processing. There have been several attempts to develop relationships between thermal conductivity, and chemical composition [45, 46]. Food components such as, carbohydrate, protein, and fat content are important parameters to design, and improve the quality of microwaved food and develop new microwave process [47].

\subsubsection{Carbohydrate}

For carbohydrate solutions the effect of free water on electrical properties becomes significant, because hydrogen bond, and hydroxyl group water interaction also play a crucial role in dielectric properties of high sugar, maltodxtrin, starch hyrolysate and lactose like disaccharide based food [48]. Carbohydrate has small dielectric properties at microwave frequencies, because it does not show dipole polarization at microwave frequencies [49]. For high carbohydrate food like instant noodles, the effect associated to stabilization of hydrogen bonding patterns through hydroxyl-water interaction. After starch bonded with water molecules through hydrogen bonding that decreased water polarization, and resulted in decreasing of the dielectric properties [50].

\subsubsection{Protein}

The dielectric properties of proteins depend upon their side chains, which may be non-polar with decreasing order of alamine, glycin, heucine, isoleucine, mathionine, phenylalanine and valine [51]. As the protein content increased, the dielectric constant, and loss factor increased. The increased of the dielectric properties with protein content was also reported for milk and soybean protein [52]. High protein content came from the addition of chicken meat which was cut, and blended by mixer prior supplement into instant noodles. Therefore, the protein became unfold that created protein denaturation and released water and dissolved ions. After that, their mobility increased which increased the dielectric properties. There was a larger increase in the dielectric loss factor than in the dielectric constant [47].

\subsubsection{Fat}

Fat has very low dielectric properties compared to water. Fat is considered inert in microwave field due to non-polar molecule that has a low interaction with polarizing electromagnetic wave. [49], indicated that with higher fat content of meat, the result of dielectric properties was lower than lean tissue meat. Additionally, the increase of fat content reduced the dielectric constant and loss factor, because the increasing of fat content diluted water ratio within the food system and resulted in the lower dielectric constant and loss factor [52]. Moreover, increasing of fat content not only reduced the interaction between food, and electromagnetic wave, but also decreased the thermal conductivity [47].

\subsubsection{Salt Solution}

Salt may be major constituent of food materials. As it is an ionic crystal it's liable for ionic conduction. When salt is added in food systems dielectric constant decreases but loss factor increases. The decrease in dielectric constant is due to water within the system which reduced the free water available for polarization, but the increase in loss factor is because of increased charged particle in the system. Salt concentration less than $1 \%$ the loss factor decrease with temperature [53], while the same increase for concentration above $1 \%$, as ionic loss is dominant for higher concentration [54].

\subsection{Uses of Dielectric Properties of Food Materials}

Dielectric properties are utilized in fruit drying processes if DH is applied Drying process are often accomplished in a short time, and provides more qualified dried products with low energy requirement [55]. Radiofrequency and $\mathrm{DH}$ also protect food materials from insects that already present in dried fruits [56]. Dielectric application is often utilized in pasteurization, sterilization, tempering of concentration of liquid foods like fruit juices. For an appropriate and uniform pasteurization process, it is crucial selecting of frequency ranges [55]. Dielectric properties are utilized in identification, processing, quality monitoring of fats and oils and improvement during oil processing and storage [57].

Dielectric heating, which includes radio-frequency (RF) and microwave (MW) treatments, has been considered as an advanced and promising technology in drying agricultural products. Some studies have indicated that RF/MW drying has advantages in improving thermal efficiency, and product quality, and in shortening drying time when contrasted with conventional drying [58-60]. However, Jiang et al found that, the drying starch using dielectric heating resulted in poor heat distribution uniformity compared to using conventional thermal energy [61].

Microwave technology was adapted to study, and assess water quality aspects [48]. They suggested that the dielectric behaviour of artificially polluted water, and polluted water collected from various industrial locations might be related for detecting the pollutants in water at $2.685 \mathrm{GHz}$ microwave frequencies based on the measurement of complex permittivity of polluted water at $27^{\circ} \mathrm{C}$. This technique could also be used to evaluate oil-water mixtures of food applications. 


\subsection{Factors Affecting Dielectric Properties of Food Materials}

The dielectric studies of food materials are an important tool to identify the quality of food materials, and to improve dielectric heating uniformity. Frequency, moisture content, phase change, and temperature are main factors that influence the dielectric properties of food materials [62].

\subsubsection{Frequency}

The dielectric constant and loss decrease with increase in frequency. These behaviors of the dielectric materials might be explained by the polarization and ionic conduction mechanism [63]. When the dielectric material is placed in an electric field as a result the dielectric is polarized which follow the external field. Since dielectric permittivity is a measure of total polarization, at low frequency the polarization follow the alternations of the field without any lag, therefore, dielectric constant of material show larger value [64]. As frequency increases the orientation of the dipole don't follow the rapid field reversal, as result oscillations will begin, it lags behind those of the field. Since dielectric constant and loss factor depends on total polarization, total polarization of the dielectric decreases $\mathrm{s}$ frequency increases [65].

\subsubsection{Moisture}

Water can exist in food materials by two alternative ways, one is free, and other is bound state. The free water is within the capillaries, and therefore bound water adsorbed to the surface of food materials. Moisture is a crucial factor which affects the dielectric constant and dielectric loss of food materials. If moisture level of food materials increases then the dipoles increases, as a result total polarization of the materials increase [66]. Therefore, as moisture increases within the material, the dielectric constant and dielectric loss increases. The dielectric loss factor is affected due to loss in free and bound waters. Calay et al reported that, the relaxations are small in microwave processing due to bound water and the loss factor is constant below critical moisture (water present in bound form) and it increase above the critical moisture level. Therefore, effects of bound water on dielectric properties are negligible [67]. The major constituents of food material are protein, carbohydrates, and salt. Protein is highly water retentive compound [68].

\subsubsection{Temperature}

Salt solution is consists of two components one is dipolar loss and other is ionic loss. Moisture and ionic conductivity affect the dielectric properties with temperature. If water is in bound morpheme and then dielectric properties increase with increase in temperature and if water is in Free State within the materials, then dielectric properties decrease with increase in temperature [69]. As a result change in dielectric properties with temperature depends on the ratio of bound and free water present within the materials. The variation of dielectric properties of materials with temperature is different for various materials, because the constituents and moisture of material vary. The dielectric properties depend on ash present within the materials. Sipahioglu et al reported that, the variation of dielectric loss of turkey meat with temperature [70].

\subsubsection{Storage Time}

The storage time can change the dielectric properties of food materials. If the food materials are placed during a humid place they can will easily absorb moisture on the opposite hand if place is dry they will can lose moisture. During study dielectric properties of mangoes at storage time $0,4,8,16$ days of storage at $210^{\circ} \mathrm{C}$. Both dielectric constant, and dielectric loss decrease with increase storage time, because moisture content reduced and it's also observed that $\mathrm{pH}$ increases during storage time, while the electrical conductivity increased with increasing temperature during the storage time [44]. Guo et al reported that, storage time play important role in freshness of shell eggs [71].

\subsubsection{Phase Change}

Change of phase is liable for a very sharp change within the dielectric properties of food materials. Thus, accurate determination of dielectric properties of frozen and partially frozen products is important to determine the rate and uniformity of heating of those products during microwave thawing [48]. The dielectric constant and the dielectric loss increase significantly when ice melts. Thus, portions of frozen products, that thaw first, can start boiling by absorbing more microwave energy, and heating up at increasing rates while the opposite portions of an equivalent product are still frozen [72].

\section{Conclusion}

This review papers covers different dielectric properties with their applications in food processing sector such as water quality detection, cereal grains, oil seeds, fruits \& vegetables, Bakery, poultry, and dairy products. Dielectric properties are used in fruit drying processes, protect food materials from insects that already present in dried fruits, pasteurization, sterilization, tempering of concentration of liquid foods such as fruit juices, identification, processing, quality monitoring of fats and oils and improvement during oil processing and storage. Various factors such as frequency, moisture content, storage time, temperature, phase change, and composition of food materials (carbohydrate, fat, and protein content) of food materials affect dielectric properties.

\section{Acknowledgements}

First, it is my pleasure to express my heart-felt appreciation and special gratitude to my advisor Dr. Helen Weldemichael for unreserved support and supervision during preparation of the review paper. I treasure she is advises which have contributed a great deal to the success of this work. 


\section{References}

[1] Palombizio, A. and V. V. Yakovlev, Parallel worlds of microwave modeling and industry: a time to cross. Microwave World, 1999. 20 (2): p. 14-19.

[2] Nelson, S. O., Dielectric properties of agricultural productsmeasurements and applications. IEEE transactions on Electrical Insulation, 1991. 26 (5): p. 845-869.

[3] Tsakama, M., et al., Physicochemical and pasting properties of starch extracted from eleven sweetpotato varieties. African Journal of Food Science and Technology, 2010. 1 (4): p. 090098

[4] Nelson, S. O., Fundamentals of dielectric properties measurements and agricultural applications. Journal of Microwave power and electromagnetic energy, 2010. 44 (2): p 98-113.

[5] Guo, W., et al., Temperature and moisture dependent dielectric properties of legume flour associated with dielectric heating. LWT-Food Science and Technology, 2010. 43 (2): p. 193-201.

[6] Tang, J., H. Feng, and M. Lau, Microwave heating in food processing. Advances in bioprocessing engineering, 2002. 1: p $1-43$.

[7] Ahmed, M., et al., The behavior of the dielectric properties of paddy seeds with resonance frequencies. IJECS, 2011. 11 (1): p. 27-32.

[8] Wang, Y., et al., Dielectric properties of foods relevant to $R F$ and microwave pasteurization and sterilization. Journal of Food Engineering, 2003. 57 (3): p. 257-268.

[9] Tıraş, B., S. Dede, and F. Altay, Dielectric Properties of Foods. Turkish Journal of Agriculture-Food Science and Technology, 2019.7 (11): p. 1805-1816.

[10] Khaled, D. E., et al., Fruit and vegetable quality assessment via dielectric sensing. Sensors, 2015. 15 (7): p. 15363-15397.

[11] Ohlsson, T., Dielectric properties and microwave processing, in Food properties and computer-aided engineering of food processing systems. 1989, Springer. p. 73-92.

[12] Nelson, S., Microwave dielectric properties of fresh onions. Transactions of the ASAE, 1992. 35 (3): p. 963-966.

[13] Nelson, S. O., Review and assessment of radio-frequency and microwave energy for stored-grain insect control. Transactions of the ASAE, 1996. 39 (4): p. 1475-1484.

[14] Engelder, D. S. and C. R. Buffler, Measuring dielectric properties of food products at microwave frequencies. Microwave world, 1991. 12 (2): p. 6-15.

[15] Bhargava, N., et al., Dielectric properties of cereals at microwave frequency and their bio chemical estimation. International Journal of Science, Environment, 2013. 2 (3): p. 369-374.

[16] Chen, J., et al., Temperature-dependent dielectric and thermal properties of whey protein gel and mashed potato. Transactions of the ASABE, 2013. 56 (6): p. 1457-1467.

[17] Maghiar, T. and D. Şoproni, Tehnica încalzirii cu microunde. 2003: Editura Universităţii din Oradea.
[18] Al Faruq, A., et al., New understandings of how dielectric properties of fruits and vegetables are affected by heatinduced dehydration: A review. Drying Technology, 2019. 37 (14): p. 1780-1792.

[19] Nelson, S., Dielectric properties of agricultural products and some applications. Research in Agricultural Engineering, 2008. 54 (2): p. 104-112.

[20] Nelson, S. and S. Trabelsi. Free-space measurement of dielectric properties of moist granular materials at microwave frequencies. in Instrumentation and Measurement Technology Conference Record. 2003.

[21] Nelson, S. O., S. Trabelsi, and S. J. Kays, Dielectric spectroscopy of honeydew melons from $10 \mathrm{MHz}$ to $1.8 \mathrm{GHz}$ for quality sensing. Transactions of the ASABE, 2006. 49 (6): p. 1977-1981.

[22] Kim, K., et al., On-line measurement of grain moisture content using RF impedance. Transactions of the ASAE, 2003. $46(3)$ : p. 861.

[23] Guo, W., et al., Frequency, moisture and temperaturedependent dielectric properties of chickpea flour. biosystems engineering, 2008. 101 (2): p. 217-224.

[24] Sacilik, K., C. Tarimci, and A. Colak, Dielectric properties of flaxseeds as affected by moisture content and bulk density in the radio frequency range. Biosystems Engineering, 2006. 93 (2): p. 153-160.

[25] Kim, Y.-R., et al., Measurement and prediction of dielectric properties of biscuit dough at $27 \mathrm{MHz}$. Journal of Microwave Power and Electromagnetic Energy, 1998. 33 (3): p. 184-194.

[26] Song, C., et al., Temperature and moisture dependent dielectric properties of Chinese steamed bread using mixture equations related to microwave heating. International Journal of Food Properties, 2016. 19 (11): p. 2522-2535.

[27] Ling, B., J. G. Lyng, and S. Wang, Radio-frequency treatment for stabilization of wheat germ: Dielectric properties and heating uniformity. Innovative Food Science \& Emerging Technologies, 2018. 48: p. 66-74.

[28] Nunes, A., X. Bohigas, and J. Tejada, Dielectric study of milk for frequencies between 1 and $20 \mathrm{GHz}$. Journal of food engineering, 2006. 76 (2): p. 250-255.

[29] Kudra, T., et al., Electromagnetic properties of milk and its constituents at $2.45 \mathrm{GHz}$. Journal of microwave power and electromagnetic energy, 1992. 27 (4): p. 199-204.

[30] Nelson, S. and P. Bartley Jr, Measuring frequency-and temperature-dependent dielectric properties of food materials. Transactions of the ASAE, 2000. 43 (6): p. 1733.

[31] Wang, S., et al., Dielectric properties of fruits and insect pests as related to radio frequency and microwave treatments. Biosystems Engineering, 2003. 85 (2): p. 201-212.

[32] Everard, C., et al., Dielectric properties of process cheese from 0.3 to $3 \mathrm{GHz}$. Journal of Food Engineering, 2006. 75 (3): p. $415-422$.

[33] Ahmed, J., H. S. Ramaswamy, and V. G. Raghavan, Dielectric properties of Indian Basmati rice flour slurry. Journal of food engineering, 2007. 80 (4): p. 1125-1133.

[34] Zhuang, H., et al., Dielectric properties of uncooked chicken breast muscles from ten to one thousand eight hundred megahertz. Poultry Science, 2007. 86 (11): p. 2433-2440. 
[35] Wang, J., et al., Dielectric properties of egg whites and whole eggs as influenced by thermal treatments. LWT-Food Science and Technology, 2009. 42 (7): p. 1204-1212.

[36] Chen, J., et al., Modeling of radio frequency heating of egg white powder continuously moving on a conveyor belt. Journal of Food Engineering, 2019. 262: p. 109-120.

[37] Dev, S., G. Raghavan, and Y. Gariepy, Dielectric properties of egg components and microwave heating for in-shell pasteurization of eggs. Journal of Food Engineering, 2008. 86 (2): p. 207-214.

[38] Sosa-Morales, M., et al., Dielectric heating as a potential post-harvest treatment of disinfesting mangoes, Part I: Relation between dielectric properties and ripening. Biosystems engineering, 2009. 103 (3): p. 297-303.

[39] Ozturk, S., et al., Dielectric properties of dried vegetable powders and their temperature profile during radio frequency heating. Journal of Food Engineering, 2016. 169: p. 91-100.

[40] Sosa-Morales, M., et al., Dielectric properties of berries in the microwave range at variable temperature. Journal of Berry Research, 2017.7 (4): p. 239-247.

[41] Nelson, S. and P. Bartley, Frequency and temperature dependence of the dielectric properties of food materials. Transactions of the ASAE, 2002. 45 (4): p. 1223.

[42] Hasted, J. B., Aqueous dielectrics. 1973: Chapman and Hall.

[43] Tereshchenko, O., F. J. K. Buesink, and F. B. J. Leferink. An overview of the techniques for measuring the dielectric properties of materials. in 2011 XXXth URSI General Assembly and Scientific Symposium. 2011. Ieee.

[44] Sosa-Morales, M., et al., Dielectric properties of foods: reported data in the 21 st century and their potential applications. LWT-Food Science and Technology, 2010. 43 (8): p. 1169-1179.

[45] Razavi, S. M. and M. Taghizadeh, The specific heat of pistachio nuts as affected by moisture content, temperature, and variety. Journal of food engineering, 2007. 79 (1): p. 158167.

[46] Marcotte, M., A. R. Taherian, and Y. Karimi, Thermophysical properties of processed meat and poultry products. Journal of Food Engineering, 2008. 88 (3): p. 315-322.

[47] Sablani, J. T. S., Effect of food chemical compositions on the dielectric and thermal properties of instant noodles with chicken meat, egg yolk and seaweed enrichment. International Journal of Food Engineering, 2017. 3 (2).

[48] Venkatesh, M. and G. Raghavan, An overview of microwave processing and dielectric properties of agri-food materials. Biosystems engineering, 2004. 88 (1): p. 1-18.

[49] Zhang, L., J. G. Lyng, and N. P. Brunton, The effect of fat, water and salt on the thermal and dielectric properties of meat batter and its temperature following microwave or radio frequency heating. Journal of Food Engineering, 2007. 80 (1): p. 142-151.

[50] Bircan, C. and S. A. Barringer, Determination of protein denaturation of muscle foods using the dielectric properties. Journal of Food Science, 2002. 67 (1): p. 202-205.

[51] Shukla, T. P. and R. C. Anantheswaran, Ingredient interactions and product development for microwave heating.
FOOD SCIENCE AND TECHNOLOGY-NEW YORKMARCEL DEKKER-, 2001: p. 355-396.

[52] Zhu, X., et al., Dielectric properties of raw milk as functions of protein content and temperature. Food and bioprocess technology, 2015. 8 (3): p. 670-680.

[53] Nelson, S. O. and A. K. Datta, Dielectric properties of food materials and electric field interactions. FOOD SCIENCE AND TECHNOLOGY-NEW YORK-MARCEL DEKKER-, 2001: p. 69-114.

[54] Nelson, S. O., Dielectric spectroscopy of fresh fruit and vegetable tissues from 10 to $1800 \mathrm{MHz}$. Journal of Microwave Power and Electromagnetic Energy, 2005. 40 (1): p. 31-47.

[55] Konak, Ü., M. Certel, and S. Helhel, Applications of microwaves in the food industry. Electronic Journal of Food Technologies, 2009. 4 (3): p. 20-31.

[56] Alfaifi, B., et al., Radio frequency disinfestation treatments for dried fruit: Dielectric properties. LWT-Food Science and Technology, 2013. 50 (2): p. 746-754.

[57] Lizhi, H., K. Toyoda, and I. Ihara, Dielectric properties of edible oils and fatty acids as a function of frequency, temperature, moisture and composition. Journal of food engineering, 2008. 88 (2): p. 151-158.

[58] Albanese, D., et al., Effects of microwave and hot - air drying methods on colour, $\beta$ - carotene and radical scavenging activity of apricots. International Journal of Food Science \& Technology, 2013. 48 (6): p. 1327-1333.

[59] Leone, A., et al., Specification and implementation of a continuous microwave-assisted system for paste malaxation in an olive oil extraction plant. Biosystems engineering, 2014. 125: p. 24-35.

[60] Wang, Y., et al., Developing hot air-assisted radio frequency drying for in-shell macadamia nuts. Food and Bioprocess Technology, 2014. 7 (1): p. 278-288.

[61] Jiang, H., et al., Effect of different dielectric drying methods on the physic-chemical properties of a starch-water model system. Food Hydrocolloids, 2016. 52: p. 192-200.

[62] Ryynänen, S., The electromagnetic properties of food materials: a review of the basic principles. Journal of food engineering, 1995. 26 (4): p. 409-429.

[63] Bao, J., et al., Dielectric behavior of Mn-substituted Co2Z hexaferrites. Journal of magnetism and magnetic materials, 2002. 250: p. 131-137.

[64] Quan, B., et al., Dielectric polarization in electromagnetic wave absorption: review and perspective. Journal of Alloys and Compounds, 2017. 728: p. 1065-1075.

[65] Michael P áMingos, D., Tilden Lecture. Applications of microwave dielectric heating effects to synthetic problems in chemistry. Chemical Society Reviews, 1991. 20 (1): p. 1-47.

[66] Sun, E., A. Datta, and S. Lobo, Composition-based prediction of dielectric properties of foods. Journal of Microwave Power and Electromagnetic Energy, 1995. 30 (4): p. 205-212.

[67] Calay, R. K., et al., Predictive equations for the dielectric properties of foods. International journal of food science \& technology, 1994. 29 (6): p. 699-713. 
[68] Xu, B., et al., Dielectric pretreatment of rapeseed 1: Influence on the drying characteristics of the seeds and physicochemical properties of cold-pressed oil. Food and bioprocess technology, 2018. 11 (6): p. 1236-1247.

[69] Sipahioglu, O., Modeling dielectric properties of foods as a function of composition and temperature. 2002, The Ohio State University.

[70] Singh, N., et al., Morphological, thermal and rheological properties of starches from different botanical sources. Food chemistry, 2003. 81 (2): p. 219-231.

[71] Guo, W., et al., Storage effects on dielectric properties of eggs from 10 to $1800 \mathrm{MHz}$. Journal of Food Science, 2007. 72 (5): p. E335-E340.

[72] Meda, V., V. Orsat, and V. Raghavan, Microwave heating and the dielectric properties of foods, in The microwave processing of foods. 2017, Elsevier. p. 23-43. 